\title{
A ABEn e a preservação da memória profissional: implantação do Centro de Memória da Enfermagem Brasileira
}

The ABEn and the professional memory preserving: the Brazilian Nursing Memory Centre implantation

$L a A B E n$ en la preservación de la memoria profesional: implantación del Centro de Memoria de la Enfermería Brasileña

\author{
Tânia Cristina Franco Santos' \\ ' Universidade Federal do Rio de Janeiro, Escola de Enfermagem Anna Nery, \\ Departamento de Enfermagem Fundamental. Rio de Janeiro-RJ, Brasil.
}

Submissão: 10-07-2013 Aprovação: 15-07-2013

\section{RESUMO}

Estudo histórico-social, que objetivou analisar e discutir a importância do Centro de Memória da Enfermagem Brasileira para preservação e divulgação da memória profissional. Utilizou-se como fontes de dados o documentário Associação Brasileira de Enfermagem: 1926-1976, além do Projeto de Implantação e do Relatório Técnico do Acervo Documental e Fônico do Centro de Memória, ambos arquivados no referido Centro. Os dados, coletados em junho de 2013, foram submetidos a crítica externa e interna, com vistas à sua validação. A análise ocorreu concomitantemente à coleta dos dados e se deu com base no conhecimento sobre o tema, apoiada pelo conceito de habitus de Bourdieu. Observou-se que, desde 1926, as diretorias da Associação Brasileira de Enfermagem contribuíram para a implantação do Centro de Memória, mediante a importância atribuída à preservação da memória. Conclui-se que a memória sacralizada no acervo constitui bem material e simbólico para a Enfermagem brasileira a ser transmitida através da historiografia dela derivada.

Descritores: Enfermagem; História da Enfermagem; Documentação.

\section{ABSTRACT}

This is a historical-social study, which aimed to analyze and argue the on the importance of the Brazilian Nursing Memory Centre for preservation and publicity of the professional memory. As data sources it was used the documentary Associação Brasileira de Enfermagem: 1926-1976, and the Project of Implantation and the Technical Report of the Memory Centre's Documentary and Phonic Collection, both filed in the referred Centre. The data, collected in June 2013, were subjected to external and intern criticism, aiming to its validation. The analysis occurred concurrently with data collection and was made based on knowledge about the topic, supported by Bourdieu's concept of habitus. It was observed that, since 1926, the directions of the Brazilian Nursing Association contributed for the Memory Centre implantation, by means of the importance attributed to the preservation of the memory. It was concluded that the memory enshrined in the collection constitutes material and symbolic goods for the Brazilian nursing to be transmitted through the historiography derived from it.

Key words: Nursing; History of Nursing; Documentation.

\section{RESUMEN}

Estudio histórico-social, que objetivó analizar y discutir la importancia del Centro de Memoria de la Enfermería Brasileña para preservación y divulgación de la memoria profesional. Como fuentes de datos, utilizó-se: el documentario Associação Brasileira de Enfermagem: 1926-1976, más el Proyecto de Implantación y el Informe Técnico del Acervo Documental y Fónico del Centro de Memoria, ambos archivados en el referido Centro. Los datos, recolectados en junio de 2013, fueron sometidos la crítica externa e interna, con vistas a su validación. El análisis ocurrió concomitantemente a la recolección de datos y se dio con base en el conocimiento sobre el tema, apoyada por el concepto de habitus de Bourdieu. Se observó que, desde 1926, las direcciones de la Asociación Brasileña de Enfermería contribuyeron para la implantación del Centro de Memoria, mediante la importancia atribuida a la preservación de la memoria. Se concluye que la memoria sacralizada en el acervo constituye bien material y simbólico para la Enfermería brasileña a ser transmitida a través de la historiografía de ella derivada.

Palabras clave: Enfermería; Historia de la Enfermería; Documentación.

\section{AUTOR CORRESPONDENTE Tânia Cristina Franco Santos E-mail: taniacristinafsc@terra.com.br}




\section{INTRODUÇÃO}

A Associação Brasileira da Enfermagem (ABEn) foi criada em 26 de agosto de 1926, sob a denominação de Associação Nacional de Enfermeiras Diplomadas (ANED). Em $1^{\circ}$ de junho de 1929, com o objetivo de ingressar no Internacional Council of Nurses (ICN) foi-lhe acrescentado ao nome o gentílico "brasileiras", tornando-se Associação Nacional de Enfermeiras Diplomadas Brasileiras (ANEDB). Esta denominação permaneceu até 7 de agosto de 1944, quando ocorre a reforma do estatuto da entidade e esta passa a se chamar Associação Brasileira de Enfermeiras Diplomadas (ABED). Em 1954, a ABED passou a ser denominada Associação Brasileira de Enfermagem, nome que permanece até os dias atuais ${ }^{(1)}$.

A ABEn tem sua origem estreitamente ligada à Escola de Enfermagem Anna Nery, criada em 1922 e implantada no Rio de Janeiro por uma missão de enfermeiras norte-americanas, patrocinadas pela Fundação Rockfeller. Diplomada a primeira turma desta escola, em 1925, as líderes de enfermagem, brasileiras e estrangeiras, tomaram a iniciativa, em 1926, de fundar a atual ABEn, a qual teve importância decisiva no desenvolvimento da Enfermagem brasileira, representando até 1973, ano de criação do Conselho Federal de Enfermagem, a única entidade organizativa da profissão ${ }^{(2)}$.

Certamente, a ideia original de uma associação de antigas alunas da Escola de Enfermagem Anna Nery tenha dado margem à fundação da ANED, pois, de outro modo as duas enfermeiras e docentes da escola, formadas no exterior, Edith de Magalhães Fraenkel e Rachel Haddock Lobo, não poderiam pertencer a Associação de Antigas Alunas; e a inexistência de uma associação contrariava os princípios apreendidos nas escolas norte-americanas sobre o desenvolvimento de uma profissão(1).

Ademais, a criação de uma associação era conveniente à Escola, pois manteria certo controle das enfermeiras por ela diplomadas, como as ex-alunas que valorizariam o seu diploma em decorrência de serem membros de uma associação ligada a uma instituição de prestígio como a Escola de Enfermagem Anna Nery ${ }^{(3-4)}$. Portanto, essas preocupações se justificavam pela necessidade de valorizar o diploma da enfermeira egressa da Escola de Enfermagem Anna Nery, uma vez que o diploma ao assegurar formalmente uma competência garante realmente a posse de um capital, tanto mais extenso quanto mais prestigioso for o documento.

Esse efeito de imposição simbólica do diploma atinge sua máxima intensidade quando atribuído por escola reconhecida, garantindo uma competência que se estende muito além do que, supostamente, é garantido por ele, com base em uma “cláusula que, por ser tácita, impõe-se antes de tudo, aos próprios portadores desses diplomas que, deste modo, são intimados a assenhorar-se realmente dos atributos que estatutariamente lhes são conferidos"(5).

Nessa lógica, compreende-se que o pertencimento à Associação Brasileira de Enfermagem agregava, desde a sua criação, capital simbólico às associadas, pois representava uma espécie de credencial que multiplicava de maneira duradoura o valor de seu portador, ao multiplicar a extensão e a intensidade da crença em seu valor ${ }^{(5)}$. Desta forma, pode-se entender o nível elevado das expectativas em relação às associadas, que refletem o reconhecimento coletivo das posições sociais.

A ABEn também foi responsável pela criação da Revista Brasileira de Enfermagem, em 1932, à época denominada Annaes de Enfermagem. A Revista Brasileira de Enfermagem, "órgão oficial de divulgação da Associação Brasileira de Enfermagem"(1), representa o primeiro espaço intelectual, no Brasil, em que as enfermeiras puderam socializar o conhecimento. Tal iniciativa constituiu indicador concreto de que a Enfermagem brasileira já havia acumulado, à época, um certo volume de experiências e reflexões sobre sua prática ${ }^{(6)}$, as quais seriam divulgadas por enfermeiras dotadas de capital de poder científico, representadas por aquelas que atuavam em instituição de ensino, em cargos de direção de serviço e instituição e a direção da própria revista; ou seja, enfermeiras reconhecidas como porta-vozes autorizadas e competentes para se manifestar em espaços públicos.

Desde a sua criação, a ABEn também vem se empenhando em organizar e preservar o seu acervo documental. Esse esforço se traduziu inicialmente pelo trabalho de suas pioneiras, no sentido de iniciar a guarda dos documentos produzidos pela Associação, ao longo de nove décadas. Essa iniciativa possibilitou a construção de um importante patrimônio para a história da saúde e da Enfermagem brasileira, mediante a massa documental representada por documentos escritos, orais e iconográficos.

Esse acervo, que sacraliza a memória, representa um bem simbólico para a enfermagem brasileira que, transmitido como herança através da produção historiográfica dele derivada, institucionaliza as lembranças e contribui para a formação de uma identidade compartilhada, a qual funciona como importante elemento de coesão dos grupos sociais, conferindo um sentimento de unidade e, por conseguinte, de filiação estatutária ${ }^{(7)}$.

Nesta edição, que celebra os 80 anos da Revista Brasileira de Enfermagem, os objetivos do presente estudo são analisar e discutir a importância do Centro de Memória da Enfermagem Brasileira para preservação e divulgação da memória profissional.

O estudo se justifica pela pertinência da preservação e disponibilização de documentos à comunidade científica de Enfermagem e áreas afins, que neles encontra as fontes indispensáveis para o trabalho historiográfico. De outra parte, o acesso às informações, pelos cidadãos em geral, contidos em documentos públicos - inscrito como direito fundamental nas constituições democráticas - garante a necessária transparência nas relações Estado-sociedade, propiciando o exercício pleno da cidadania.

\section{MÉTODO}

Trata-se de estudo histórico-social, em que se utilizou como fontes históricas o documentário intitulado Associação Brasileira de Enfermagem: 1926-1976; o Projeto de Implantação e o Relatório Técnico do Acervo Documental e Fônico do Centro de Memória da Enfermagem Brasileira, ambos de autoria de Ivone Evangelista Cabral e arquivados no referido Centro de Memória. Os critérios que nortearam a seleção dessas fontes foram orientados pela possibilidade de divulgar a importância 
do acervo da Associação Brasileira de Enfermagem e de aprofundar as reflexões sobre os jogos de forças que determinaram a constituição e preservação da memória da instituição, materializada nos documentos. Neste aspecto, o estudo agregou valor ao conhecimento científico já publicado, quando traz a lume as imbricações entre memória e história.

A coleta dos dados ocorreu no período de 13 a 30 de junho de 2013. Após a seleção dos dados, como preconiza o método histórico, procedeu-se à crítica externa e interna. $\mathrm{Na}$ crítica externa, indagou-se a autenticidade dos documentos, considerando sua procedência, autoria e natureza. Sobre a crítica interna buscou-se apreender o conteúdo, considerando a qualidade e relevância da informação contidas nos documentos selecionados $^{(8)}$. Esse processo permitiu a validação das fontes históricas selecionadas para o estudo.

A análise ocorreu de forma simultânea à coleta dos dados e se deu com base no conhecimento produzido sobre o tema e no conceito de habitus do sociólogo francês Pierre Bourdieu. A utilização desse conceito se justifica pelo entendimento de que o trabalho historiográfico requer a compreensão dos interesses que nortearam a produção e preservação da memória institucional, materializadas nos documentos. Isso porque o habitus representa uma forma de memória, pois a produção e reprodução de lembranças, bem como os esquecimentos resultam do aprendizado das disposições inerentes à identidade instituída, de modo a conservar as condições de preservação de tal identidade.

O presente estudo vincula-se a projeto de pesquisa aprovado pelo Comitê de Ética e Pesquisa da Escola de Enfermagem Anna Nery / Hospital São Francisco de Assis, em 26 de março de 2009, sob o número de Protocolo 04/2009.

\section{RESULTADOS E DISCUSSÃO}

\section{Centro de Memória da Enfermagem Brasileira - lugar de memória da enfermagem}

A compreensão para além da metáfora da aceleração da história evoca a necessidade de preservação dos lugares onde a memória se cristaliza e se refugia. Essa preocupação deriva da conscientização de que "a ruptura com o passado se confunde com o sentimento de uma memória esfacelada, mas onde o esfacelamento desperta ainda memória suficiente para que se possa colocar o problema de sua encarnação"(9).

Os lugares de memória comportam, simultaneamente, as dimensões material, simbólica e funcional, uma vez que mesmo um arquivo, cuja aparência é puramente material, se reveste de simbolismo desde a sua concepção; mesmo um plano de aula, um programa de evento ou um manual cujas características são tipicamente funcionais comportam uma natureza simbólica, se concebidos como ritual; mesmo um minuto de silêncio que parece o exemplo extremo de uma significação simbólica é, ao mesmo tempo o recorte material de uma unidade temporal que representa a evocação concentrada de uma lembrança ${ }^{(9)}$.

Os arquivos históricos, como lugares de memória que são, representam instâncias fundamentais para a compreensão de eventos pretéritos já que abrigam uma diversidade de documentos, os quais precisam ser analisados em seu conjunto; nas suas especificidades; no que apresentam em comum; nas suas contradições; no que se guardou para que fosse lembrado e também no que não se guardou, determinando o esquecimento ou o desconhecimento ${ }^{(10)}$. Isso porque o trabalho historiográfico encontra-se circunscrito pelo lugar que define sua conexão do possível com o impossível, ou seja, com os lugares que permitem e interditam as produções históricas, tornando possíveis certas pesquisas e impossibilitando outras ${ }^{(11)}$.

Outro aspecto importante sobre a memória é que as lembranças são construídas a partir das relações que envolvem lugares, tempo e pessoas, uma vez que as memórias individuais ou coletivas se fazem em algum lugar que lhes imprime uma referência. Nesses lugares, os indivíduos ou grupos estão em constante disputa de poder, e é justamente essa disputa que determina o que será lembrado e o que será esquecido(7), portanto memória e história são construtos sociais, ainda que aparentemente definidas e construídas pelas subjetividades dos indivíduos, pois, mesmo suas manifestações mais individualizadas dependem da interação social, já que esses passam sua existência em grupos, num complexo processo de construções identitárias ${ }^{(12)}$.

Portanto, a memória coletiva, imposta e defendida mediante um trabalho especializado de enquadramento, é perpetuada através dos diversos documentos produzidos de acordo com as relações de poder então existentes, as quais são expressas tanto nas narrativas, como nos silêncios ou lacunas desses documentos ${ }^{(7)}$.

Memória e história evocam o passado. No entanto, a compreensão da importância dos lugares de memória remete ao entendimento das especificidades conceituais dos termos "memória e história", uma vez que a memória é um fenômeno sempre atual e, por isso mesmo, "está em permanente evolução, aberta à dialética da lembrança e do esquecimento, inconsciente de suas deformações sucessivas, vulnerável a todos os usos e manipulações, susceptível de longas latências e repentinas revitalizações"(9). Já a história representa a construção de uma versão sobre um passado que não existe mais, se configurando como uma operação intelectual que demanda análise e discurso crítico $^{(9)}$.

O conhecimento de um passado comum é importante para preservação dos diversos grupos sociais e "constitui-se aspecto imprescindível ao estabelecimento de identidades calcadas em experiências compartilhadas, não somente no campo histórico ou material, como também (e sobretudo) no campo simbólico"(10).

Essa simbiose entre memória e identidade profissional remete a consciência da necessidade de preservação da memória através da constituição e da preservação de acervos, pois a memória é fio condutor que liga as gerações umas com as outras, dando caráter de antiguidade, ubiquidade e continuidade. Sobre esse aspecto, a memória coletiva, "além de uma conquista, é também um instrumento e objeto de poder, pois é vital para os grupos e as sociedades que lutam por reconhecimento" $^{\prime \prime(13)}$.

A preservação da memória da Enfermagem brasileira sempre foi preocupação das sucessivas diretorias da Associação 
Brasileira de Enfermagem, desde a sua criação em 1926. A massa documental acumulada e preservada reflete o zelo, especialmente das Presidentes da entidade, com a guarda, organização e classificação preliminar do acervo. No curso de 87 anos de existência da entidade, cada diretoria contribuiu para que, na atualidade, o Centro de Memória da Enfermagem Brasileira, inaugurado em 4 de agosto de 2010, na sede da ABEn Nacional, em Brasília-DF, constituísse uma realidade ${ }^{(14)}$. Por isso mesmo, enquanto instituição que abriga a memória da profissão, o Centro de Memória da Enfermagem Brasileira deve ser concebido como herança material e simbólica.

Essa concepção demanda a necessidade de docentes e pesquisadores, especialmente, de história da enfermagem, empreenderem estratégias para que os estudantes de enfermagem possam compreender a relação entre memória e identidade profissional, através da aquisição de um capital cultural que lhe possibilite a condição de herdeiro da memória da enfermagem brasileira. Isso porque o habitus - disposição incorporada que funciona como princípio gerador de práticas distintas e distintivas ${ }^{(5)}$, é também uma forma de memória porque a produção e reprodução de lembranças comuns, bem como os esquecimentos, resultam de disposições incorporadas, ou seja, de impulsos para adotar comportamentos como aceitáveis ou adequados a responder as contingências da realidade social.

Como manifestação emblemática e pioneira da conversão da massa documental em lugar de memória tem-se o valioso documentário, intitulado Associação Brasileira de Enfermagem 1926-1976, publicado em 1976, de autoria de Anayde Corrêa de Carvalho. Esse documentário, sempre atual, reproduz cabalmente a importância da preservação das fontes documentais, pois as fontes históricas, enquanto significantes da memória se constituem matéria-prima do trabalho historiográfico, o qual é sempre tributário da interlocução com o documento.

Centro de Memória da Enfermagem Brasileira - concepção e organização

O acervo documental da Associação Brasileira de Enfermagem conta com aproximadamente 170 metros lineares de documentos textuais referentes ao período de 1926 a 2019, constituídos de relatórios, correspondências, dissertações e teses, cartazes de eventos promovidos pela entidade, anais de congressos, dissertações e teses, coleção completa da Revista Brasileira de Enfermagem (obra rara do acervo e da Enfermagem brasileira), entre outros, os quais foram previamente higienizados, organizados e classificados.

O acervo conta ainda com cerca de 2.700 fotografias (em branco e preto ou coloridas) em suporte de papel, guardadas em pastas de papel e armazenadas em caixas de arquivos. $\mathrm{O}$ acervo conta também com três álbuns. Os documentos fonográficos envolvem fitas cassete com suas respectivas transcrições, de entrevistas realizadas com personagens da enfermagem brasileira.

O projeto original de tratamento do acervo, denominado de "Preservação e Difusão do Acervo Documental", foi elaborado na gestão 2004-2007, sob a Presidência de Francisca Valda da Silva, quando o Centro de Estudos e Pesquisa em
Enfermagem/CEPEn da ABEn foi dirigido interinamente por, Isabel Cristina Kowal Olm Cunha e, posteriormente, por Josete Luzia Leite ${ }^{(14)}$.

A gestão 2007-2010 da ABEn, sob a Presidência de Maria Goretti David Lopes e Diretoria do Centro de Estudos e Pesquisa em Enfermagem de Ivone Evangelista Cabral, transformou o projeto de "Preservação do Acervo Documental da ABEn" em projeto de implantação do "Centro de Memória da Enfermagem Brasileira". Essa transformação implicou em adequação teórico-metodológica e ajustes orçamentários, para atender as diretrizes do Fundo Nacional da Saúde, do Ministério da Saúde, o qual viabilizou parte da execução orçamentário do projeto ${ }^{(14)}$.

Para a organização do Centro de Memória, a Associação Brasileira de Enfermagem buscou parceria com o Núcleo de Pesquisa de História da Enfermagem Brasileira / Escola de Enfermagem Anna Nery / Universidade Federal do Rio de Janeiro $^{(16)}$. Um novo convênio, em 2009, com validade de cinco anos, foi firmado com a Escola de Enfermagem Anna Nery ${ }^{(14)}$.

Entre os propósitos de implantação do Centro de Memória da Enfermagem Brasileira destacam-se: assegurar condições adequadas de higienização, exposição, digitalização e preservação dos documentos existentes; organizar o acervo documental segundo a natureza dos documentos; divulgar o acervo, mediante a elaboração de catálogos escritos e virtuais; disponibilizar os produtos resultantes da organização, de modo a viabilizar o acesso via internet; garantir a segurança física do acervo histórico da Associação Brasileira de Enfermagem $^{(15)}$.

Para viabilizar a implantação do Centro de Memória, desenvolveram-se quatro subprojetos, executados simultaneamente: I. organização e adequação do ambiente; II. tratamento do acervo documental textual; III. tratamento do acervo documental iconográfico; IV. tratamento técnico do acervo documental fonográfico ${ }^{(15)}$.

O desenvolvimento do projeto para implantação do Centro de Memória foi coordenado pela diretora do CEPEN e teve início em 2009. Na ocasião, foi dada continuidade ao trabalho de diagnóstico pormenorizado da situação do acervo, iniciado na gestão anterior, contemplando o estudo da área física, de modo a atender ao Subprojeto I - Organização e adequação do ambiente para funcionamento do Centro de Memória da Enfermagem Brasileira. Sendo assim, constatou-se que a área destinada ao acervo ocupava um espaço de aproximadamente $90 \mathrm{~m}^{2}$, o qual contava com janelas envidraçadas, sem grades de proteção, em toda a extensão lateral da sala. Essas janelas permaneciam abertas durante o horário comercial, em face da temperatura ambiente, pois não havia climatização na sala.

Evidências da temperatura e umidade relativa do ar alta no ambiente foram detectadas mediante a visualização de colônias de fungos nos documentos. Sinais de temperatura e umidade relativa do ar baixas no acervo também foram percebidos, pois alguns documentos apresentavam-se distorcidos e ressecados. Essas ocorrências derivam também da ausência de climatização do ambiente, tornando-o vulnerável às frequentes oscilações de temperaturas (extremamente nocivas para os documentos), pois todos os materiais encontrados nos 
acervos são higroscópicos, isto é, absorvem e liberam umidade muito facilmente e, portanto, se expandem e se contraem com as variações de temperatura e umidade relativa do $\operatorname{ar}^{(17)}$.

A ausência de climatização do ambiente também prejudica o controle da qualidade do ar (aspecto essencial para a conservação de acervos), uma vez que os poluentes contribuem significativamente para deterioração dos documentos. Portanto, as janelas abertas durante o horário de expediente do acervo facilitavam a entrada de poluentes externos como o dióxido de enxofre, óxidos de nitrogênio e o Ozônio, os quais provocam reações químicas, com a formação de ácidos que causam sérios danos aos materiais.

Apesar das vidraças das janelas estarem protegidas por filmes e persianas, havia intensa entrada de luz natural no ambiente pelo fato das mesmas permanecerem abertas. Qualquer exposição de luz, mesmo que por pouco tempo, é nociva ao documento e o dano é cumulativo ${ }^{(17)}$. Na área externa às janelas, observou-se um pátio gramado, com algumas árvores frutíferas. Havia entrada de fuligens e poeira na sala através das janelas abertas. Os danos derivados da exposição à luz se evidenciaram através da identificação de documentos escritos e fotográficos com sinais de esmaecimento, com implicações diretas relativas à legibilidade. Em termos de iluminação artificial, constatou-se a necessidade de diminuição da intensidade da luminosidade.

Assim, foram realizadas reformas e adequação da área física para a instalação do Centro de Memória. Tal reforma não comportou acréscimo de área construída, consistindo em isolamento da área do acervo, substituição de estrutura do piso para a instalação de arquivos deslizantes, recuperação de materiais de acabamento e adequação das instalações existentes, com destaque para a criação de espaços para: o arquivo histórico / permanente; o arquivo intermediário; a sala para higienização dos documentos, a consulta do usuário; a guarda de pertences dos usuários; e os banheiros.

A adequação da área física comportou o trancamento das janelas e colocação de filmes protetores. O ambiente foi climatizado e por medidas de segurança promoveu-se a instalação de circuito interno de TV. Além disso, o acesso ao acervo passou a comportar apenas uma porta de entrada.

Para o desenvolvimento do Subprojeto II - Documentos textuais: tratamento técnico do acervo, estudos foram realizados com vistas à definição de rotinas de tratamento destinadas a desacelerar os processos de degradação e aumentar a vida útil do suporte dos documentos. Também foram definidas as normas que deveriam orientar a utilização do acervo.

No que se refere ao diagnóstico pormenorizado das condições de conservação dos documentos textuais constatou-se que os documentos escritos foram submetidos, parcialmente, a algum tipo de organização que teve como objetivos garantir as condições de adequadas de conservação, organização e acesso. Não obstante, verificou-se a necessidade imperiosa de implementar intervenções relativas a higienização, estabilização (mediante retirada de agentes que danificassem os documentos como clipes, grampos, fitas adesivas, entre outros) e restauração daqueles com comprometimentos como manchas de excrementos de insetos e rasgos que pudessem comprometer a sua leitura. Os documentos foram armazenados em caixas de material neutro apropriadas. Também foram colocadas capas de material neutro em cada documento.

Foram tratadas 482 caixas-box de documentos textuais (aproximadamente 67 metros lineares de documentos). O tratamento previsto inicial era de 60 metros lineares, porém algumas caixas estavam vazias e, para complementação, foram tratadas mais 25 caixas de documentos. Além destas, foi acrescentado o tratamento de mais 27 caixas de documentos, uma vez que só foi possível o tratamento de 43 fitas de vídeo (Subprojeto IV - Tratamento técnico do acervo documental fonográfico) $)^{(18)}$.

Foram tratados (higienizados, organizados, classificados) também 19 exemplares de Anais de Congressos, 70 exemplares de dissertações ou teses, 39 exemplares da revista Annaes de Enfermagem, além de outras 24 obras raras. No que concerne a obras raras, os dados foram inseridos no sistema, contemplando nove classes, em conformidade com a técnica arquivística, assim descrita: "Informações sobre Pesquisas e Pesquisadores em Enfermagem, Prêmio Enfermeira do Ano, Obras de Referência / Manuais Técnicos, Guias de Referência, Monografias, Normas/Documento/Histórico, Biografias e a revista Annaes de Enfermagem ${ }^{(18)}$.

No tocante ao desenvolvimento do Subprojeto III - Tratamento do acervo documental iconográfico, foram tratadas 543 fotografias de diversos eventos e personalidades. Observou-se que as fotografias já possuíam uma prévia descrição, com a identificação de alguns dos presentes na composição fotográfica, bem como algumas anotações no verso da fotografia como data, local e evento. As fotografias foram higienizadas, sendo estabilizadas em suporte de papel para uso específico de preservação e conservação de documentos e armazenadas em caixas de material neutro.

Observou-se também a necessidade de digitalização de todo o acervo, para posterior organização e classificação em consonância com técnica arquivística. Essa estratégia facilitará a difusão do acervo, bem como sua preservação, através da minimização dos riscos relativos à utilização inadequada pelos usuários, bem como sua exposição dos efeitos nocivos da luminosidade, seja ela natural ou artificial.

A etapa I do tratamento do acervo documental textual, iconográfico e fonográfico envolveu a seleção de materiais, segundo a linha do tempo das gestões das Presidentes da entidade e a periodização de 1926-1947; 1947-1972; 1972 a 2009. Nesta etapa de implantação do Centro de Memória, para viabilizar sua execução com o orçamento disponível, priorizou-se o tratamento da totalidade dos documentos correspondentes aos dois primeiros períodos. No último período, pinçaram-se documentos pontuais segundo a classificação do plano documentalista apresentado pela arquivista responsável pelo tratamento do material ${ }^{(18)}$.

A conclusão da etapa I comportou a execução de quatro subprojetos, gerando os seguintes produtos: ambiente adaptado para a guarda do acervo, em condições que asseguram sua preservação; documentos textuais, iconográficos e fonográficos tratados, classificados, incorporados ao acervo e catalogados em banco de dados, à disposição da comunidade científica da saúde e da sociedade, em geral. 


\section{CONSIDERAÇÕES FINAIS}

A compreensão da sociedade enquanto construção histórica remete a necessidade de preservação da memória. Nesse processo, ao tempo em que o grupo tende a se dotar de meios para além da finitude das pessoas e instituições, também procedem ao controle das lembranças e, por conseguinte o controle da história digna de ser contada.

A compreensão da importância atribuída pela Associação Brasileira de Enfermagem como a guarda e preservação de seus documentos produzidos ao longo de várias décadas sob a ótica de Pierre Bourdieu, no tocante ao conceito de habitus proporcionou evidências de grande densidade cognitiva, as quais possibilitaram a compreensão de estratégias de fabricação do simbólico pelas integrantes da Associação Brasileira de Enfermagem, em estreita vinculação com as instituições de ensino de enfermagem.

A preservação dos documentos históricos, lugares de memória, representa o grande desafio para a enfermagem brasileira, pois o que está em jogo na memória é a (re) construção e preservação da identidade profissional e institucional. Nesse processo, os documentos precisam ser interpretados em conformidade com as conjunturas que determinaram sua produção, veiculação e preservação.

\section{REFERÊNCIAS}

1. Carvalho AC. Associação Brasileira de Enfermagem (1926-1976): documentário. Brasília: ABEn; 1976.

2. Baptista SS, Barreira IA. Enfermagem de nível superior no Brasil e vida associativa. Rev Bras Enferm 2006;59 ( ${ }^{\circ}$. esp.):411-16.

3. Barreira IA, Baptista SS. O movimento associativo das enfermeiras diplomadas na primeira metade do século 20. Rev Bras Enferm 2001;54(2):157-73.

4. Borenstein MS, Padilha MIC, Caetano TL, Mancia JR. Hilda Anna Krisch: pioneira na enfermagem catarinense - formação e contribuição. Rev Bras Enferm 2004;57(3):366-70.

5. Bourdieu P. A Distinção: crítica social do julgamento. Porto Alegre: Zouk; 2007.

6. Santos TCF, Gomes MLB. Nexos entre pós-graduação e pesquisa em enfermagem no Brasil. Rev Bras Enferm 2007;60(1):91-5.

7. Santos TCF, Barreira, IE, Gomes MLB, Baptista SS, Peres MAA, Almeida Filho AJ. A memória, o controle das lembranças e a pesquisa em história da enfermagem. Esc Anna Nery Rev Enferm 2011;15(3):616-25.

8. Padilha MICS, Boresntein MS. O método de pesquisa histórica na enfermagem. Texto Contexto \& Enferm 2005;14(4):575-84.

9. Nora P. Entre memória e história: a problemática dos lugares. Projeto História 1993;10(1):7-28.

10. Oliveira AJB. História, memória e instituições: algumas reflexões teórico-metodológicas para os trabalhos do Projeto Memória SIBI/UFRJ. In: Oliveira AJB, organizador. Universidade e lugares de memória. Rio de Janeiro: Universidade Federal do Rio de Janeiro Sistema de Biblioteca e Informação / 2008. p. 41-60.

11. Certeau M. A escrita da história. 2. ed. Rio de Janeiro: Forense Universitária; 2002.

12. Oliveira AJB. Os conceitos de educação, história, memória e identidade como constructos sociais. Linguagens, educação e sociedade 2012;17(26):147-70.

13. Barreira IA. Memória e história para uma nova visão de enfermagem no Brasil. Rev Latino-Am Enferm $1999 ; 7(3): 87-3$.

14. Cabral IE, Lopes MGD. Apresentação do Centro de Memória da Enfermagem Brasileira. Hist Enferm Rev Eletronica 2010;1(1):210-19.

15. Cabral IE. Projeto Centro de Memória da Enfermagem Brasileira. Brasília; 2008.

16. Cunha ICKO. O CEPEn e a produção e difusão do conhecimento da enfermagem brasileira [editorial]. Rev Bras Enferm 2005;58(1):5-5.

17. Sauthier J, Carvalho MTC, Santos NMP. Centro de Documentação da Escola de Enfermagem Anna Nery (EEAN) uma contribuição à História da Enfermagem. Rev Latino-Am Enferm 2000;8(5):81-4.

18. Cabral IE. Relatório Técnico do Acervo Documental, Iconográfico e Fônico do Centro de Memória da Enfermagem Brasileira. Brasília; 2009. 